\title{
The ambivalent role of water at the origins of life
}

\author{
ANDREY DO NASCIMENTO VIEIRA ${ }^{1}$, KARL \\ KLEINERMANNs ${ }^{2}$, WiLliam F. MARTIN ${ }^{1}$, MARTINA \\ PREINER $^{1}$ \\ ${ }^{1}$ Institute for Molecular Evolution, University of Düsseldorf, \\ 40225 Düsseldorf, Germany \\ ${ }^{2}$ Institute for Physical Chemistry, University of Düsseldorf, \\ 40225 Düsseldorf, Germany
}

Without water as a solvent and reactant, life as we know it would not exist. However, water molecules can also counteract the formation of essential organic molecules due to hydrolysis. This conundrum constitutes one of the central issues in origin of life research. Hydrolysis is an important part of energy metabolism but only because inside a cell, it is a controlled reaction. How could hydrolysis have been regulated under prebiotic settings? Lower water activities possibly provide an answer. Geochemical sites with less free and more bound water can supply the necessary conditions for protometabolic reactions. Such conditions occur in serpentinizing systems, hydrothermal sites that synthesise hydrogen gas via rock-water interactions. We summarise the parallels between biotic and abiotic means of controlling hydrolysis in order to narrow the gap between biochemical and geochemical reactions, and outline how hydrolysis could even have played a constructive role at the origin of molecular self-organisation. 